Entrevista

\title{
La Pedagogía de la Ternura - Una lucha por la dignidad y la vida desde la acción educativa
}

\author{
The Pedagogy of Tenderness -A struggle for dignity and life \\ from the educational action \\ Alejandro Cussiánovich Villarán* \\ coordinacion@ifejant.org.pe \\ Entrevistado por: Christine Schmalenbach** \\ christine.schmalenbach@tu-dortmund.de
}

ISSN 1996-1642, Editorial Universidad Don Bosco, año 9, No. 16, julio-diciembre de 2015, pp. 63-76. Recibido: 21 de abril de 2015. Aprobado: 16 de junio de 2015

Resumen

La Pedagogía de la Ternura surgió en un contexto de guerra interna en Perú. Un grupo de maestros buscaba respuesta a la violencia e indiferencia que afectaban sus vidas y la de sus estudiantes. Es un enfoque con una vista respetuosa e integral de la infancia, tomando en cuenta no solo la cognición de los estudiantes sino también sus experiencias diarias, sus emociones y relaciones interpersonales. La idea fue y es desarrollada por colaboradores del Manthoc e IFEJANT, dos organizaciones que apoyan a niños trabajadores en la defensa de sus derechos. Tiene antecedentes y movimientos hermanos en otros países con experiencias semejantes.

Palabras clave: Pedagogía, ternura, dignidad, educación, jóvenes
Abstract:

The Pedagogy of Tenderness arose in the context of internal conflict in Peru. A group of teachers was searching for an answer to the violence and indifference affecting their lives and those of their students. The approach holds a respectful and integral view of children, taking into account not only their cognition but also their everyday experiences, their emotions and their interpersonal relationships. The idea was and is developed by coworkers of the Movimiento de Adolescentes y Niños Trabajadores Hijos de Obreros Cristianos (Manthoc) and IFEJANT, two organizations that support working children in their struggle for their rights. It has roots and related movements in other countries with similar experiences.

Keywords:Pedagogy, tenderness, education, dignity, youngsters

* Doctor honoris causa por la U.N. Frederico Villareal en 2008, docente en la Universidad Mayor de San Marcos (UNMSM), miembro del consejo directivo de Instituto de Formación de Educadores de Jóvenes, Adolescentes y Niños Trabajadores (IFEJANT), Perú

** Licenciada en Educación Especial por la Ludwigsburg University of Education en Alemania. Docente e investigadora en la Facultad de Ciencias de Rehabilitación de la TU Dortmund University en Alemania. 


\section{Introducción}

Alejandro Cussiánovich Villarán es maestro de educación primaria y sacerdote católico con un trasfondo salesiano (con estudios en el seminario salesiano de Magdalena del Mar, en Inglaterra y en Lyon). Desde más de medio siglo ha estado acompañando y apoyando a niños y jóvenes en su camino, sobre todo en el Perú. Como maestro joven, en el año 1958 descubrió la realidad de los niños trabajadores y se dio cuenta que la escuela tradicional pasaba por alto la experiencia y las necesidades de este grupo de trabajadores y estudiantes. En 1976 fue uno de los iniciadores del Movimiento Nacional de Niños y Adolescentes Trabajadores Hijos de Obreros Cristianos (Manthoc). Este movimiento da a niños, niñas y adolescentes que tienen que trabajar para apoyar a su familia, la oportunidad para unirse solidariamente y apoyarse en la defensa de sus derechos (Cussiánovich 2010a; Grández Moreno, 2014). En este contexto y como respuesta a la realidad cruda que vivían los niños y niñas así como las y los maestros en los tiempos del conflicto armado en Perú entre los años 1975 hasta finales de 1990, se concibió la idea de la Pedagogía de la Ternura, descrita detalladamente en varios textos (Cussiánovich 2010a, 2010b; Schibotto 2013). En 1989 junto con el Manthoc, la Juventud Obrera Cristiana (JOC), el Programa Internacional para la Erradicación del Trabajo Infantil (IPEC, por sus siglas en inglés) y las Mujeres Trabajadoras del Hogar dan inicio al Instituto de Formación de Educadores de Jóvenes, Adolescentes y Niños Trabajadores (IFEJANT), espacio de formación para los adultos que acompañan procesos de formación y organización de jóvenes, adolescentes, niños y niñas, y del que hoy es miembro.

La presente entrevista tuvo lugar en el contexto de la reunión anual de niños, niñas y adolescentes trabajadores organizada por Manthoc en Chosica, Perú, el 16 de Noviembre 2012. En esta entrevista, Alejandro Cussiánovich habla sobre lo que él llama la Pedagogía de la Ternura, sus trasfondos actualidad y futuro. El texto aquí presentado, fiel a su espíritu, ha sido validado por el mismo Cussiánovich. 


\section{Entrevista}

\section{Cristine Schmalenbach (C. S.): ¿Me podría dar una breve definición de qué es la Pedagogía de la Ternura?}

Alejandro Cussiánovich (A. C.): Yo no soy muy amigo de definiciones.

\section{S.: Okay.}

A. C.: Pero sí de nociones. Es decir: ¿Qué subyace en todo esto? La Pedagogía de la Ternura se inscribe dentro de una corriente que tiene larga historia en el pensamiento pedagógico, en particular, en el occidental. Tiene que ver con, por ejemplo, cuando en el siglo diecinueve se hablaba de una pedagogía basada en la amorevolezza, como dicen los italianos. Es decir, en una capacidad de afectuosidad respetuosa, en una relación marcada por el componente emocional, afectivo, por los sentimientos, como una manera de establecer un vínculo emancipador. En materia educativa y pedagógica, si no se establece un vínculo constructivo y positivo, no hay proceso educativo.

Entonces, la Pedagogía de la Ternura quiere recordar -en una etapa como estade finales de siglo XX y primeros lustros del siglo XXI, en la que hay una hegemónica tendencia a enfatizar los aspectos digamos más racionales, la tecnología, la cultura informática, la comunicación globalizada y la ética en la que se inscribe, vale decir, una sociedad que propugna el individuo asocial. Pero donde también se da la proclamación del individuo como tal en donde pareciera que te tienes que revestir de cierto cinismo, de cierta dureza, para no dejarse arrastrar por sentimientos hacia aquellos sectores que consideramos carenciados, que no han entrado total y plenamente en la órbita de la globalización, del consumo, de una globalización del mercado, aunque tengan la conciencia ocupada por lo que dicha "sociedad escaparate o vitrina" les ofrece.

Entonces, recordar esta otra dimensión creo que puede contribuir a establecer un equilibrio en que no se trata de renegar de nada de lo que el progreso tecnológico aporta, sino de no olvidar de que hay una dimensión de contagio, que es lo que Wallon llama la segunda piel. Es decir, todo el mundo de la subjetividad.

Y no es que actualmente la sociedad dominante no tome en cuenta eso, sino que lo instrumentaliza en función del consumo, del mercado y de lo que podríamos llamar la manera más personal, mejor, individual más que personal, de afirmarse frente a los demás. Entonces, estamos una sociedad competitiva, en donde la competencia deja siempre eso que hasta el propio Banco Mundial llama el "costo del progreso", que tiene que haber gente que se queda atrasada, que tiene que haber gente que cae en la pobreza. O sea, el costo del desarrollo es también parte de la explicación cínica que se da sobre el crecimiento de las gentes que quedan excluidas o desafiliadas de esa dinámica. Y ahí, nos guste o no, hay todavía el inmisericorde argumento de decir que es un problema 
de tiempo y es un problema de esfuerzo personal. En otras palabras, es una sociedad en la que si triunfas es tu mérito y si fracasas es tu problema. Eso es lo que algunos están llamando el individualismo o el individuo asocial. Es decir, es él el centro de su propia vida y la razón de existir de lo que hace. Es una valoración del individuo, es absolutamente correcta y necesaria, pero es una valoración del individuo al precio de dejar de lado, por lo tanto, la sensibilidad, capacidad para que se conmuevan las entrañas frente a aquello que niega la humanidad y la responsabilidad de apurar los procesos de humanización.

La novedad no está tanto en hablar de Pedagogía de la Ternura, sino fundamentalmente en reconocer que tenemos un modelo de sociedad que utiliza el mundo de la sensibilidad, de los sentimientos, en función de colocarte ideales detrás de los cuales tienes que perseguir o articular tu vida, pero al precio de que haya otras vidas que se quedan marchitas, truncas en su condición humana.

Entonces, lo principal, parece, es ese reconocimiento de dos tendencias: El reconocimiento de una tendencia de endurecimiento frente al dolor y al sufrimiento por un lado; y dos: Lo que podríamos considerar también la utilización del sentimiento en función de la resignación o de la conformidad con los acontecimientos que no dependen de uno. La Pedagogía de la Ternura intenta, creo yo, tocar ese mundo interior, ese mundo interno como un componente necesario de la lucha por la dignidad, de la lucha por la libertad, de la lucha por el bienestar.

Podríamos afirmar que la Pedagogía de la Ternura, es una pedagogía antagónica y confrontacional contra todo intento de reeditar aquello de la servitude volontaire (servidumbre voluntaria).

Ahora, esto siempre todavía en el mundo de una cultura más occidentalizada. Porque en el mundo de nuestras culturas originarias, la vida emocional y afectiva incluye la relación con la naturaleza. Entonces, no podría haber una Pedagogía de la Ternura con una relación solo interpersonal, sino cómo nos relacionamos con los fenómenos del medio ambiente. Y ahora has podido constatar que hay regiones en el país y en algunas comunidades, donde la relación con el mundo de las plantas, con el mundo de los cerros, y que para algunos es considerado como un pensamiento y un sentimiento arcáicos o hasta cierto punto míticos. ¿Pero dime tú si en el conjunto de la sociedad no nos movemos por creencias, por apuestas, por sentimientos? Yo sé que hay sectores gruesos de la sociedad que han eliminado todo atisbo de sentimiento o de romanticismo en las cosas. Entonces, ¿cómo se es más cerebrales, más racionales?, ¿cómo devolverle a esta otra dimensión, no el relegamiento al mundo de lo privado, de lo personal, y de lo individual, lo psicologista, sino devolverle la fuerza política, la fuerza social, la capacidad de incidir en la vida global y no solamente como a un producto de consumo interno?

La Pedagogía de la TernuraUna lucha por la dignidad y la vida desde la acción

64. educativa
Yo resumiría esto quizás de esta forma. La Pedagogía de la Ternura quiere recuperar y contribuir a hacer de la relación interpersonal una relación social 
y una relación que tiene que ver fundamentalmente con el sentido social y político en el cual los seres humanos estamos inscritos, ¿no? Por ahí iría más o menos.

\section{S.: En su ensayo "Aprender la condición humana" varias veces hace referencia a las raíces peruanas y el contexto peruano de esa pedagogía. ¿Cree que también se puede trasladar a otros países Latinoamericanos?}

A. C: Creo importante la pregunta que haces. El origen del discurso, de un discurso sobre la Pedagogía de la Ternura en nuestro caso, tiene lugar en un contexto negador de esa dimensión. Eso está puesto ahí desde el principio en el ensayo que señalas.

\section{S.: Sí.}

A. C.: En el sentido de que en un país con una guerra interna, con la experiencia de negación de todo sentimiento, con la necesidad de endurecerse para no sufrir ante la negación de la fraternidad, del respeto a la vida, pero del respeto también a la vida de los animales porque tanto el ejército como algunos de los grupos alzados en armas una manera de someter era no solamente a través de esas prácticas usuales en muchas guerras, o en todas las guerras, como es la violación de mujeres, el asesinato de dirigentes, pero también la matanza de los propios animales. Para un campesino, matarle una vaca, era como hacerle perder un miembro de su familia. En un contexto en que las cosas pierden paradójicamente su sentido normal; por ejemplo, decir la verdad es un riesgo y mentir es en contra de la conciencia de uno. Entonces, los campesinos, obligados a decir lo contrario de lo que sabían, eso crea un tipo de relación consigo mismo que merma energías. Entonces, la Pedagogía de la Ternura nace como una respuesta a algo que se negaba en ese contexto.

Es curioso que un psiquiatra como Restrepo, colombiano, pueda ser discutible en su imagen, hoy política. Pero no entro en eso, quien describe en el contexto un país con guerra interna de hace más de sesenta años y desde una ciudad como Medellín que estuvo totalmente trajinada por la guerra, guerra de guerrilla, guerra antisubversiva, etc. Entonces, es curioso que en el extremo de una situación se piense exactamente lo qué fue lo que nos pasó. ¿De qué vamos a hablarles a los maestros que han visto matar a sus colegas, que han visto matar a sus alumnos, que han visto desaparecer a los padres de familia, que han destrozado su escuela o que la han llenado de pintas? O que ha llegado el ejército y les decía: "Si ustedes apoyan a los grupos alzados en armas, Ustedes son parte de ellos." Y en escarmiento, o mataban o llevaban presos o desaparecían a pobladores. ¿De qué hablamos? Hay que recuperar lo que la guerra niega, o nos hace perder.

Esa perspectiva tiene que ver con una realidad concreta. No tanto con las culturas en ese momento, sino con una realidad de resquebrajamiento de sentidos comunes, en donde un autor que escribió los cuentos en Ayacucho, 
ilustrados con dibujos de niños de la guerra, decía: Cuando se les explica a los niños el cielo como el lugar, el firmamento donde está el sol, de donde viene la lluvia para los campos, una cosa positiva, y de ahí llegaron los helicópteros que traen fuego, que traen bombas, que traen muerte. Entonces, uno dice: ¿Qué pasa arriba? No, topográficamente, significando una cosa positiva y rica para el desarrollo de la vida, ahora de arriba, de lo alto, viene la muerte. La muerte llega también del mismo lugar de donde creíamos que solo llegaba la vida. Esto rompe aspectos simbólicos, destruye un imaginario y no te lo sustituye sino por un imaginario negativo de destrucción. ¿Cómo repercute eso en el aula, en el proceso educativo? La Pedagogía de la Ternura no es solo para colegio, es para las relaciones comunitarias, para las relaciones familiares, para todo. Pero en el aula hay una contradicción con niños que cuando tienen que dibujar, cuando tienen que decir cómo ven ellos la situación, pintan dolor, pintan muerte, pintan de dónde viene la muerte, la muerte viene de arriba, cuando se les había dicho: "Arriba está la felicidad".

Esa contradicción es parte del contexto en el cual la Pedagogía de la Ternura viene a decir: "No matemos la poca sensibilidad, la imaginación, las creencias y mitos que teníamos". Porque todos vivimos de creencias, de mitos, y no solo de ideas y de grandes principios y definiciones, ino es cierto? Entonces, creo que la Pedagogía de la Ternura es una respuesta de negación de la negación, como dirían algunos. Es decir, negar a la vida, hay que afirmar, negado el sentimiento. En las escuelas de preparación de la tropa para ir a los combates, lo primero que hacen, es disecar tus sentimientos. No puedes sentir nada porque si sientes, no actúas a tiempo. Entonces, eso se instala también en la comunidad. No puedo sentir porque va a haber muerte en cualquier momento.

Hay un caso que lo recoje la comisión de la verdad y la reconciliación de una persona que no se resistía, una mamá que no se resistía a enterrar a su hijo que lo habían matado y estuvo con su hijo muerto en la cama acompañándolo durante días. Y uno dirá: ¿Pero cómo? Esa mujer por qué no quería desprenderse del cadáver de su hijo. Pero hay que entenderlo de otra manera, ¿no es cierto? Es decir: Ahí, me parece, había una especie de decir: "Lo que salió de mis entrañas, ¿por qué me lo han matado?" Y un poco como que la cercanía era de decir: "Esto no es justo. Yo estoy con él. No le puedo devolver la vida que yo le di, pero no es justo que me lo hayan matado." Para algunos será una mujer sádica que quiere convivir con la muerte. No era convivir con la muerte como la entendemos nosotros, más urbana y occidentalmente, sino que era convivir con la negación de la vida, cuando para ella ese cadáver era de su hijo, era SU hijo, y es que en el fondo se había negado la vida y ella clamaba por esa vida segada. Estamos ante una cercanía de rebelión, de dolida protesta.

La Pedagogía de la TernuraUna lucha por

la dignidad y la vida desde la acción

66. educativa
Entonces, ahí hay una necesidad de entender que el núcleo es la negación y la Pedagogía de la Ternura es un grito de la rebeldía frente a eso. La Pedagogía de la Ternura te viene en una especie de rechazo radical de lo que niega la 
relación humana más estrecha, más profunda. De otro modo, los discursos de la Pedagogía de la Ternura son un engaño, pues, ¿acaso no podría serlo?

Por ahí creo que hay un elemento que podría ayudarnos a entender algo que el propio título dice: "Aprender la condición humana". Pero esto sale al encuentro de un texto de Edgar Morin que titula: "Los siete saberes necesarios de la educación para el siglo XXI" y ahí él habla de enseñar la condición humana. Yo no sé si hay que enseñar, hay que aprenderlo, icierto? Entre todos vamos aprendiendo. Pero me parecía interesante que él hablara del hecho de que hay que intentar que la gente entienda que la condición humana es una condición que tiene que ver con el entorno porque tiene que ver también con esta otra dimensión de ser humanos, etc. Me pareció mejor, como somos aprendices a nuestra condición de ir siendo humanos, ya que nunca terminamos de aprender. Siempre hay dimensiones nuevas.

Y todo ello no es un problema solo cerebral, de conocimientos, es también de subjetividad. Por eso es que hay una categoría, que creo que no se trabaja en el libro, categoría que emplea otra autora quien habla de sensimiento. Sensimiento, neologismo que tiene que ver con sensibilidad y pensamiento. Es decir, no hay pensamiento que no venga envuelto en sentimiento, en sensibilidad. Y esto sí me parece interesante porque en nuestras culturas originarias, no es una definición cerebral la que te dan. Sino que dicen: "Esto es lo que yo siento y lo que yo vivo. Después tú me lo podrás explicar". Por ejemplo, el concepto de equivalencia, esa es una categoría nuestra, pero ellos no hablan de equivalencia, sino que viven el hecho de que podemos entre adultos y los que no son adultos, podemos intercambiar y el uno es el otro.

Escribir y pretender definir algo que inequívocamente lo separe al distinguirlo, es como disecar algo. Disecar algo para quedarse con la forma de un ser vivo y para guardarlo en un museo, pero ya sin vida. Eso es lo que tenemos, a veces, la impresión cuando uno escribe algo. Es como disecar la vida. Le quitas el dinamismo. Y ahí creo que la idea esta del mundo de la subjetividad, que no es un problema solo postmoderno, ino!, sino que es parte de esto que Morin llama "enseñar la condición humana" que nosotros hemos preferido llamar "aprender la condición humana". Por ahí veo yo un poquito lo que me preguntas, si no me equivoco.

\section{S.: Ya me contó de la experiencia de Colombia. ¿Usted conoce otras experiencias semejantes de otros países, donde surgió una idea semejante?}

A. C.: En Cuba, Turner y Pita han escrito, el 2002, un pequeño pero valioso texto en el marco del pensamiento de José Martí, al respecto. En Argentina hay gente ahora que está trabajando lo de la Pedagogía de la Ternura. Es interesante pues Argentina pasó por una situación igual muy dura. Muy brutal. Hay un compañero psicoterapeuta, Ignacio Berasain, que ha escrito un libro que se titula La ternura, ese sentimiento proscrito, prohibido porque suena a intimidad, a sentimentalismo, a romanticismo. Y que no es por ahí que se cambia el mundo, no. Es que no 
es con sentimientos que se cambia el mundo. Pero para un educador, una educadora, un terapeuta en el caso de él, es un mundo fundamental. Hablar de resiliencia, la capacidad entonces de hacer las cosas bien, no obstante los traumas por los cuales uno haya podido pasar o que las circunstancias sean malas, me parece que recoge de alguna manera esa perspectiva de hacer de esta dimensión -una dimensión social-y políticamente válida para enfrentar la vida y para no dejar que la última palabra esté en manos de la fatalidad y del destino sino en el reconocimiento de que hay voluntades políiticas detrás de todo esto. Para el bien como para el mal. Para ser, digamos, constructores de felicidad o destructores de elementos de felicidad. Entonces, están trabajando esto. He visto también que en Google aparecen varios materiales al respecto, en You Tube, un evento sobre la Pedagogía de la Ternura que me parecía interesante. No conocía eso.

Entonces, recientemente hay trabajos pero quizá tendríamos que ligar esto, yo lo dije al principio, con aquello de la pedagogía de la amorevolezza de los italianos del siglo XVII y XVII, y además habría que ligarlo con lo que Paulo Freire escribe de la Pedagogía de la Esperanza. Como pedagogía también, yo diría, de la cercanía, de la amabilidad, del buen trato. Entonces, por lo menos lo que conozco en Argentina es de este compañero que está muy preocupado y que ha encontrado en otros países gente que está trabajando en lo mismo y que de alguna manera quisieran; él quisiera formar como una red de reflexión al respecto. Yo he fallado un poco en esto porque no soy muy devoto de cosas electrónicas y cosas por el estilo, pero creo que es un buen empeño el que él está realizando. Entonces, sí hay, me parece, en todas partes.

Pero sin hablar de Pedagogía de la Ternura, hay escritores que han recogido el drama que supone toda negación de la dignidad; por ejemplo, Boris Cyrulnik que estuvo en campo de concentración durante la Segunda Guerra Mundial, que es psiquiatra y que también dice: "Oye, esto es importantísimo, esta otra dimensión. Hay una energía, una reserva de humanidad que retrabajar. Y como él, seguramente hay otros. Ernst Bloch fue un filósofo, un teólogo que trabajó este componente; entonces en donde haya habido el drama humano de la guerra y de otras formas de violencia y negación, siempre han surgido estas otras maneras de querer entender la vida, de querer reivindicar la dimensión donde se juega el sentido de la vida y la vida misma. Porque lo que está en juego no es solamente un problema de agresión sino un problema de tocar la profundidad del ser humano. Algo, yo diría de lo que podríamos recoger de Freud, cuando él habla del malestar en la cultura. $O$ sea, hay algo que no camina. Ese malestar, ¿cómo lo abordo? Lo tomamos en cuenta o no. Entonces, los niños que llegan al aula, los niños que llegan al grupo, no son solamente aprendices y estudiantes, sino que ellos traen un mundo emocional. Lo que Wallon llama la segunda piel, lo que está por debajo de lo que aparece. Trabajar eso, es parte de la Pedagogía de la Ternura, que se enriquece de la psicología, que se enriquece ahora de las neurociencias. Hay cantidad de caminos que no se han trabajado, que yo no he trabajado, y que habría que retrabajar. Para entender mejor cómo no estamos hablando de 
cuestiones emocionales en el sentido de la debilidad de las emociones y no de la racionalidad, sino diciendo que sensimiento quiere decir lo que siento y lo que pienso.

Articular nuestras ideas, como exigencia porque las ideas, además, expresan sentimientos y además, producen sentimientos. Cómo el lenguaje expresa y produce sentimiento. De trabajar esa dimensión, creo yo es una parte que toca la Pedagogía de la Ternura. Hay una larga agenda abierta al respecto, ¿no?

\section{S.: Ya ha mencionado a Paulo Freire. ¿Cuál es la relación entre la Pedagogía de la Ternura y la pedagogía de Paulo Freire? ¿En qué son semejantes o en qué se difieren?}

A. C.: Uy!, a ver. De Paulo yo creo que hay que recoger el hecho de que él ha sido una persona muy, muy sensible. Y por lo menos sectores que trabajamos en la educación aquí en el Perú en los años 70 éramos bastante críticos de Paulo Freire porque veíamos que no tenía un análisis más marxista, más desde una perspectiva de contradicciones de clase, etc. Era el reproche que se le solía hacer a las propuestas de Paulo, y que estaba más en la onda de educación liberadora, la liberación, pero de esa perspectiva cristiana y de su sensibilidad como educador. Pero Paulo Freire ha tenido la virtud no solamente de pensar, buen pensador, creo yo, en materia educativa a partir de la experiencia en lo que ha vivido acompañando a grupos de base en su país, y más allá. El hecho de haber sido deportado quiere decir que lo que él hacía, tenía un impacto políitico, constituía una real amenaza para el poder establecido.

Nosotros quizás no supimos leer siempre esa otra manera de hacer política, que no era la declaración verbal, decir: "Me inscribo en esta perspectiva sociológica o no".

Paulo se ha abierto de forma, en mi opinión muy importante y significativa, a entrar por otro lado en lo que él ha hecho de alfabetización. El tema no solo es aprender a leer y escribir, sino aprender a entender la propia vida y el propio contexto. Después vamos a escribir sobre eso, después vamos a aprender a leer, pero ya sabemos leer antes de aprender a leer. ¿Me explico? Uno tiene que aprender a leer en profundidad el mensaje que la experiencia cotidiana nos va dejando. Y después vas a aprender a leerlo eso sobre un texto escrito cuando aprendas a escribir, y manejes los signos y su fuerza simbólica, ¿no? Entonces, eso a veces no se entendió en algunos sectores nuestros. Otros, creo que sí entendieron bien. Yo me inscribo en los que estábamos en duda de todo eso, que no éramos muy devotos de eso.

Pero en una oportunidad, en un contacto con Paulo Freire acá en Lima, él vino en el año setenta y uno, si no me equivoco, fue interesante porque él llegó para dar una conferencia a los maestros, como quinientos maestros en el clima de la reforma educativa y Paulo empezó a decir lo siguiente: "Eu tenho saudade de mia mulhier." Es decir: "Estoy con nostalgia, estraño a mi mujer." Los maestros 
que estaban en plena lucha, ideas, ideología, cambio, revolución, la nueva educación en el Perú, gente de izquierda, muchos de ellos, etc, etc.: "¿Y qué viene a decir este Señor?" "iQue está con nostalgia!" Y dijo: "Yo tengo nostalgia de mi mujer, de mi esposa". "¿Qué es esto?" iChoque! ¿Por qué está hablando de su esposa? ¿Qué esposa? O sea, la reacción era: "Alguien que está en la lucha, no está pensando en su hijo, su hija, ien su mujer! Pensando en lo que hay que hacer, ¿no?" Y es que había toda una formación política como desgarrada de este submundo de la subjetividad, del mundo personal, que se considera algo doméstico y no político, algo en la intimidad y no de la lucha social. Había esta división en muchos, muchísimos de nosotros, creo yo, hay que reconocerlo.

Entonces Paulo Freire viene casi llorando y era la primera vez que se iba a encontrar con los maestros ahí en una reunión grande e importante. Y él dijo unas cosas: Nos dijo, "He estado trabajando en muchos países. Llego acá, estoy cansado. Yo lo que quisiera tener ahora es el calor y el cariño, la voz de mi esposa". Bueno, la crítica fue muy dura. Bueno el contraste era mayor, pues antes que Paulo, Iván Illich se había pegado una intervención cargada de fuego, de radicalidad y de fuerza de arrastre y movilización. Se comprende entonces, por qué había docentes que decían por Paulo: "Este está atrasado". Pero cuando uno piensa a fondo, nos estaba dejando un mensaje distinto. Nos estaba diciendo: "No hay solamente ideología. Hay otras dimensiones de la vida. Y el educador no puede dejar eso de lado". Más tarde Paulo se preguntará "¿Dónde andan hoy los radicales que me criticaban hace unas décadas? ¿Cuántos arrepentidos hay entre ellos?"

Cosa que uno aprendió cuando era profesor de aula, quizá. Cuando un niño te llega tarde, no cumple con las tareas, entonces, y es mi historia personal, a un niño en el año 58 lo dejé fuera del aula por incumplido empedernido y le dije: "Espérame afuera del salón. No entras todavía." Después de unos minutos salí y le digo: "¿Qué pasó?" "Ah", me dijo: "le voy a contar". Y me empezó a contar su historia. Yo descubrí un mundo en esta criatura. Porque él trabajaba. Yo no sabía que trabajaba. Yo lo miraba solo como alumno en el aula. Resultó que este niño trabajaba muy temprano, a las cinco de la mañana se iba hacia Carabayllo al norte de la ciudad, al campo, zona agrícola, compraba cosas y llevaba a la mamá que iba a trabajar en un restaurante, a cocinar. Y él, cuando terminaba las clases, me dijo, a las cinco de la tarde él se iba al restaurante donde estaba su mamá, ayudaba a la mamá a atender a los clientes que venían, solo cuando se iba el último borracho él podía limpiar, levantar las sillas, sentarse y empezar a estudiar. Eso me cambió la vida pues yo dije: Lo tomo al niño solo como estudiante, alumno, ¿no? ¿y su historia? ¿y su vida? Que es una dimensión que no es solo de datos biográficos, sino de vivencia, de sentimiento.

La Pedagogía de la TernuraUna lucha por la dignidad y la vida desde la acción

70. educativa
Freire nos coloca ese tema, de decir: "iOjo! Somos seres humanos". La educación no puede ser meramente cognitiva. No podemos estar solo con el paradigma del conocimiento: Buen alumno, el que sabe. Entonces, todo ese cuestionamiento no se entendió mucho. Lo que aporta Freire es una gran sensibilidad por partir de las personas y por al mismo tiempo recuperar esa dimensión como parte 
también de la labor educativa. Claro, tu habrás leído el texto del ensayo sobre pedagogía de la ternura como me dices, y no habrás encontrado muchas citas a Paulo Freire, pero la experiencia como docente en 1958 y escucharlo en 1971 y llegar a entenderlo críticamente o más en profundidad en los 90 , constituye un significativo aprendizaje para mí.

\section{S.: No. Por eso quise preguntar.}

A. C.: ¿Te das cuenta?

\section{S.: Sí.}

A. C.: Porque ahora se está recuperando a Freire, se lee más, y hay cosas muy, muy sugerentes y útiles que vienen surgiendo de releer y recrear a Freire. Pero yo guardaba esa otra imagen al decir: Ah, cuando yo fui crítico de lo que Freire planteó que tiene pena o nostalgia de su mujer...y a mí me parecía poco importante, no por la mujer, sino porque me decía entonces: "Y qué tiene que venir con estos sentimientos acá, si ese es su problema personal". Eso ha cambiado y ser crítico no es desconocer lo que a uno mismo le falta y lo complejo e incierto de lo que también otros van planteando. Creo que hay una recuperación de Paulo Freire muy importante también desde nuestro lado de la educación popular. Tengo la percepción que para importantes sectores en Europa, Paulo Freire es casi un ídolo en el buen sentido. Lo he constatado en Bélgica, lo he visto en Francia, en Suiza... y tienen razón. Porque es una lectura más compleja, no es una lectura solo de una dimensión ideológica o de una técnica educativa o didáctica. Paulo Freire es un ser humano en primer lugar. Yo sí creo que él tiene anotaciones que podrían haber enriquecido el pensamiento de la Pedagogía de la Ternura. Quizás sería una tarea pendiente para retomar porque la Pedagogía de la Ternura, desde sus primeras intuiciones en 1992, interesa seguirlas trabajando. Y creo que Freire puede ser leído por algunos, y me incluyo, de una manera mucho más abierta y recuperando esta otra dimensión que él colocó el año setenta y uno, que a mí me chocó, pero que después, pensando, pensando, yo dije: "iQué interesante!" aunque me tardé más de veinte años para entender el mensaje que traía.

\section{S.: Gracias. En su ensayo menciona varias veces que aún no hay una metodología o una didáctica. Qué diría usted, ¿con cuáles criterios tendría que cumplir una metodología para poder ser asociada con la Pedagogía de la Ternura?}

A. C.: Claro, pero también se dice que eso no lo construye una persona, sino que tiene que ser hecho colectivamente. Porque creo que en este campo, la preocupación central era decir: "Ojo ante tanto maltrato, tanta muerte, tanta desgracia de la guerra interna, recuperemos esta dimensión. Si no, nunca jamás habrá democracia y paz." Esa fue la preocupación inicial con la que nace este discurso de Pedagogía de la Ternura. 
Pero creo que estamos en otra etapa y habría que volver a repensar los aspectos, primero el contenido, o sea, hacia dónde y cómo. Pero no ha habido tiempo para procesar los aspectos metodológicos. Es decir, lo intentamos en las escuelas de niños trabajadores. Hay varias propuestas de cómo colocar "Aprender la condición humana" dentro del currículo, y no ha sido fácil. Porque el maestro te dice: "Bueno, ¿y criterios de medición?" O te dice: "¿Cuáles son los indicadores de desarrollo?" Nosotros hemos procedido por olfato, por intuición. Pero hoy día te lo exigen más técnicamente, ¿no es cierto?

Entonces, la respuesta, que no es una respuesta de evasión, es: "Eso lo tenemos que hacer entre todos, hay que compartir la experiencia". ¿Cómo haces tú en tu relación personal, interpersonal? Es que es una cuestión que hay que encasillar dentro de la propuesta curricular o no. Los maestros durante los últimos cinco años siempre han dicho: "Interesante como concepción la Pedagogía de la Ternura, pero nos falta saber cómo se hace eso en concreto". Ese tema es un capítulo abierto, te lo digo con toda sinceridad. Yo sí creo que hay elementos, por ejemplo, toda esa metodología de partir de la vida, de la vida cotidiana, y ahí, intentar ver el porqué, qué consecuencias, y qué pasa de las condiciones de las personas en todo eso. Pero no está sistematizado. Creo que es una deficiencia que arrastramos.

Entonces, el texto producido es un aporte solo para decir: "Oye, y este aspecto del trabajo educativo, ¿está presente o no está presente? ¿O somos repartidores de ideal, o somos repartidores de ideas?" ¿Me dejo entender? Te diría que personalmente, no hemos dedicado tiempo y cuando se ha desafiado a colegas a que lo hagan, no ha habido tampoco una respuesta más formal. Ese es un capítulo abierto para mí. ${ }^{3}$

\section{S.: ¿Qué papel juega la cooperación o la colaboración entre los niños en la Pedagogía de la Ternura? Yo he visto que trata mucho de la relación del maestro con el alumno. ¿Qué tal la relación entre los alumnos?}

A. C.: Bueno, yo te diría que con el bullying que está de moda en las escuelas, hay como una negación de esto. Nosotros no hablamos de Pedagogía de la Ternura con los niños, sino de la importancia de cultivar la amistad, el respeto y también la solidaridad.

En el movimiento ha habido experiencias muy interesantes con eso que no hemos sistematizado. Por ejemplo, los chicos y chicas -nosotros no hemos hecho distinción entre varón y mujer- porque ellos nos enseñaron eso. Por lo tanto, cuando había eventos en el movimiento, chicos y chicas dormían juntos. Hoy ya sería un escándalo, ¿no? Los padres van a decir: "No, ¿qué pasó ahí?" No pasa nada. O sea, no es muy natural. En tu cultura eso es absolutamente

72. educativa
3. En el tiempo entre la realización de la entrevista y su publicación se ha publicado el libro "Educar desde la Diversidad: Una pedagogía y una Práctica desde los Niños, Niñas y Adolescentes Trabajadores" (Schibotto 2013), que propone la didáctica por proyectos como una posible práctica afiliada a la Pedagogía de la Ternura. 
corriente, acá no. Acá había una división muy, muy discriminadora entre varones y mujeres. Tampoco eso puede parecer a promiscuidad, falta de respeto. Porque había un gran sentido de respeto y de amistad y hasta de cariño, entre los chicos, las chicas, pero muy lindo. Eso puede venirse al piso, sí. Eso hoy día podría ser malinterpretado, es verdad. Pero sí ha habido ese tipo de experiencias. Ese grupo que tú ves aquí, es un grupo nuevo. En el $85 \%$ de niños y niñas que incluso ya son hijos de una cultura distinta con matices distintos en relación al mundo adulto. En otras épocas eran mucho más abiertos. Hoy día son más reservados. También porque tienen un mundo personal que, al parecer, no tenía la generación anterior. El solo hecho de que tengan sus aparatos, su celular, cabinas de Internet, se relacionan con anónimos, y menos con sus pares cercanos en el espacio y el tiempo. Antes no existía nada de eso, o sea, o hablabas o te comunicabas, o nada. Ahora: "Te mando. Me copias. Te feiceo. Nos encontramos en el twitter..." Entonces, te das cuenta cómo esta es una nueva generación que no nos ha dado el tiempo suficiente quizá, para pensar cómo se establece el nexo de amistad, de respeto y de cariño entre ellos. Estamos en eso.

He venido a esta reunión y estoy observando a estos nuevos chicos. He estado durante estos treinta, casi cuarenta años en esto, pero esto es otra cosa. Entonces, yo estoy observando y viendo y digo: Hmm, aquí hay cosas parecidas a las anteriores, de otras generaciones, pero hay cosas que no había antes y que ahora son parte de las nuevas subjetividades. Y eso tiene que ver con que cada cual es cada cual. Esa es una constitución de subjetividades distintas en estos últimos siete, ocho, diez años. Nunca tuvimos un niño como ahora acá que tiene su propia computadora pequeñita Sansumg, no sé si has visto. Qué es lo que quiero decir, ese es el indicador de que hay una manera distinta de relacionarse entre ellos también. Por un lado, hay más expresiones de cercanía, pero marcadas por una cierta banalización de las relaciones. Es lo que yo percibo, ¿no? Si tú te sientas en el comedor, yo estaba viendo, no son capaces de seguir hablando sobre qué les ha parecido lo tratado en la reunión, y es que están en otra. Hemos tenido generaciones en que podíamos terminar una sesión y seguían y en la mesa ellos decían: "Oye, sí, me ha parecido, pero habría que..." O sea, estaban entonados. Estos no, estos son: Plic, se acabó, ploc, vuelvo a enchufar. Y lo hacen, ino? O sea, como que desenchufan, van a otra cosa, enchufan, y entran en otra. No es que antes no haya habido también diversión y ganas de chancear, sí lo ha habido. Pero creo que estos tienen una tendencia, una mayor necesidad de confraternizar, verdad, pero no a partir de lo serio, de lo consistente, que consideramos serio y consistente. Anoche decían, por ejemplo, que el problema mayor es la comunicación. Justo cuando todos tienen Facebook, Twitter y tienen esto, y tienen 50,000 cosas, y todavía dicen: "El problema mayor es que no nos comunicamos". Entonces, son interrogantes que se nos abren para pensar. No tenemos una respuesta. Yo no tengo una respuesta. Pero lo que sí es importante es que en los grupos más estables sí hay una relación amical e interesante, una preocupación, una solidaridad, entre chicos y chicas. Creo que sí. Pero no lo hemos medido en términos de cuánto eso aporta a una reflexión de la perspectiva de la Pedagogía de la Ternura. Creo que habría que hacerlo de forma más reposada. 


\section{S.: ¿Qué pueden hacer los maestros para aportar a la amistad entre los chicos?}

A. C.: Por un lado, en un clima en que se sospecha sistemáticamente de la relación del adulto con los menores por problemas de pedofilias, de acoso, entonces, eso influye también en estas dimensiones.

C. S.: Bueno, pues, muchas gracias. Ya llegué al final de mis preguntas, ¿quisiera añadir algo que no pregunté?

A. C.: No. Lo más importante para mí, creo, es cómo confrontar esta Pedagogía de la Ternura con las nuevas subjetividades emergentes. Dos, con los nuevos desafíos didáctico-pedagógico-metodológicos, y tres, con la historia. No solo Paulo Freire, sino qué se puede enriquecer como pensamiento pedagógico a partir de la historia, de la historia anterior y reciente. Y también que hay un aporte desde las experiencias del mundo médico, en lo psiquiátrico, psicológico, de la post-guerra. A mí me parece que ahí hay cosas lindas que hay que aprender, que los de otras generaciones nos toca aprender, estoy convencido.

\section{S.: Muchas gracias.}

A. C.: Soy yo que te agradezco.

\section{Referencias}

Cussiánovich Villarán, A. (2010a). Aprender la Condición Humana. Ensayo sobre pedagogía de la ternura. 2a ed. Lima: Ifejant.

Cussiánovich Villarán, A. (2010b). Ensayos sobre infancia II. Sujeto de derechos y protagonista. 1a ed. Lima: Ifejant.

Grández Moreno, H. (2014). Maestro de la Ternura. En: El Peruano, 7 de noviembre 2014, p. 7. Recuperado el 17 de abril de 2015:

http://www.elperuano.pe/Edicion/suplementosflipping/variedades/392/index.html.

Schibotto, G. (2013). Educar desde la Diversidad. Una Pedagogía y una Práctica Didáctica desde los Niños, Niñas y Adolescentes Trabajadores. Lima: CIFA Onlus \& IFEJANT 